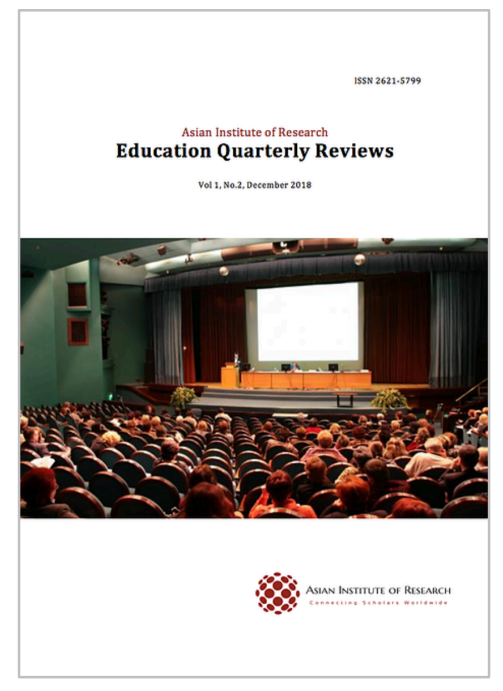

\title{
Education Quarterly
} Reviews

\author{
Ahmad, Irma, and Abidin, Mohamed Jafre Zainal. (2018), A Conceptual \\ Framework in Developing an Alternative Listening Comprehension Test to \\ Profile Learners' Performance. In: Education Quarterly Reviews, Vol.1, No.2, 240- \\ 247.
}

ISSN 2621-5799

DOI: 10.31014/aior.1993.01.01.25

The online version of this article can be found at: https://www.asianinstituteofresearch.org/

Published by:

The Asian Institute of Research

The Education Quarterly Reviews is an Open Access publication. It may be read, copied and distributed free of charge according to the conditions of the Creative Commons Attribution 4.0 International license.

The Asian Institute of Research Education Quarterly Reviews is a peer-reviewed International Journal. The journal covers scholarly articles in the fields of education, linguistics, literature, educational theory, research, and methodologies, curriculum, elementary and secondary education, higher education, foreign language education, teaching and learning, teacher education, education of special groups, and other fields of study related to education. As the journal is Open Access, it ensures high visibility and the increase of citations for all research articles published. The Education Quarterly Reviews aims to facilitate scholarly work on recent theoretical and practical aspects of Education. 


\title{
A Conceptual Framework in Developing an Alternative Listening Comprehension Test to Profile Learners' Performance
}

\author{
Irma Ahmad ${ }^{1}$, Mohamed Jafre Zainal Abidin ${ }^{2}$
}

\author{
${ }^{1}$ Academy of Language Studies, Universiti Teknologi MARA, Negeri Sembilan, Malaysia \\ ${ }^{2}$ School of Educational Studies, Universiti Sains Malaysia, Penang, Malaysia \\ Correspondence: Irma Ahmad, Academy of Language Studies, Universiti Teknologi MARA Cawangan Negeri \\ Sembilan, Kampus Seremban 3, Negeri Sembilan, Malaysia. Tel: +60197598177. E-mail: irma@ns.uitm.edu.my
}

\begin{abstract}
This conceptual paper addresses the information in developing a comprehensive listening comprehension test to profile learners' listening performance based on international standards. Listening is a fundamental skill in which students need to gain adequate proficiency for their successful in communication and academic achievement. Underpinned by tenets derived from three flagship models and approach- Socio-cognitive Framework for Developing Test of Listening by Weir, the Cognitive Processing Model by Geranpayeh and Taylor, and General Language Ability and Listening Ability Model by Rost - a framework is conceptualised. The conceptual framework clarifies the interplay of the four notions and their connections which will inform the main purpose of the study that is to develop a listening comprehension test to benchmark and profile the undergraduate students in Malaysia.
\end{abstract}

Keywords: Conceptual Framework, Listening Comprehension, Testing Listening, Listening Performance, Benchmarking, Profiling

\section{Introduction}

\subsection{Introduction}

Listening is known as a receptive skill, which involves the process of interpreting messages of what is said. It allows them to understand what they hear and take part in any form of successful communication. While listening to lectures or class discussion, students are expected to respond appropriately, to ask the speaker to repeat or to clarify what they have said. However, if the lectures or classes are conducted by using the English language, the process of comprehending the lectures and information will be challenging especially to the students with low proficiency in the English language.

In Malaysia, the English language is learned as a second language and like in many language settings worldwide, listening is widely acknowledged as a neglected skill due to insufficient pedagogical development and even in teacher training (Mendelson, 2001; Rost, 2002; Vandergrift, 2007; Field, 2008). Although listening is important in comprehending lectures, previous researchers have discovered that at schools, students were not exposed to listening comprehension process as more attention was given on other skills like reading and writing (Selamat and Sidhu 2011). In fact, listening has not been given the treatment or status in most English language learning 
classroom in Malaysia (Suchitra, Koo and Kesumawati 2014). By the end of secondary or post-secondary school, students are expected to gain sufficient mastery of all the skills in the English language including listening to enable them to study effectively at tertiary levels and to use the language whenever necessary in everyday situations and their future career. However, findings from a collaborative baseline project in 2013 by the Ministry of Education (MOE) and Cambridge English Language Assessment (CELA) contradicts with the above expectations. Moreover, listening is found to be neglected, and little attention was given on both listening comprehension process and assessment (Robinson et al. 2014). At the moment, there is no benchmarking or a stand-alone test on students' listening abilities except for the Malaysian University English Test (MUET).

\subsection{Problem Statement}

Although MUET is a test of language proficiency and largely used for university admission, unfortunately, it does not provide enough information specifically on the students' listening abilities. The MUET band description indicates students' listening ability in general, and it does not achieve the main aim of getting information on how good or what students can do base on their test score. At present, listening has been included in the latest curriculum of the primary and secondary school in Malaysia, and yet there is still lack of research and documented academic work done locally in determining the ESL listening skills abilities of the students especially among the undergraduate students. In fact, reports from the Malaysian Examination Council indicate very poor performance on listening components of MUET from the year 2010 until 2015 (Official Portal Malaysian Examination Council 2010-2015). Overall, the result indicates that almost all the candidates fall at Band 1 which indicates below expected levels of performance for tertiary education. Band 1 is considered as an extremely limited user in MUET Band description. Majority of candidates scored Band 2 and below on November 2015 which depicted an alarming situation where listening should then be given more attention like reading and writing. Feedback from the teachers from baseline study indicated that the students do not, in general, put much effort into learning English, and some have negative attitudes and low motivation. Therefore, there is a need to develop an alternative listening comprehension test that is compatible and could be used to benchmark and profile the students' listening ability so that their performance could be monitored and enhanced to fit the expectation of being undergraduate students. Besides, once the students know how to listen to learn, they will not be left behind as they are able to comprehend lectures and participate in classroom discussions.

\section{Literature Review}

There is no doubt that listening skill is important in daily life. It is very important skills as human beings spend a considerable amount of their time engaged in communication and other activities that required listening with it. The importance of listening is not just a matter of time on task. It is a critical factor for academic success. Generally, teachers expect students to listen consistently with a cognitive load which they would be putting on their students during instruction both in classroom interaction or in group discussions. In a spoken message, 55\% of the meaning is translated non-verbally, $38 \%$ is indicated by the tone of voice, while only $7 \%$ is conveyed by the words used (Mehrabian 1981). Therefore, as a student, they need to integrate both verbal and nonverbal information while listening to their teachers. Learning will be more likely difficult then how it supposed to be if teachers fail to consistently produce the oral messages across the verbal and nonverbal signal. In fact, it has been proven that students who listen effectively are more successful in their schoolwork and in their achievement levels and among college students who fail, lacking listening skills were a stronger factor than reading skills or academic aptitude (McDevitt, Sheenan and McMenamin 1991).

Although testing listening comprehension is one of the major concerns of language testing for decades, there has been relatively little research on how to measure listening comprehension in a reliable and valid manner. In fact, from a review of the literature, there is no generally accepted theory of listening comprehension that suggests on which best to base these tests. Brown states in his book that "we must rely as much as possible on observable performance in our assessments of students" (2004, p.117). As a result of the process of listening cannot be observed directly, the result of test taker's auditory processing can only be observed in the form of spoken or 
written responses (Brown 2005). Therefore, in order to test students' listening proficiency, testers need to consider many important details in developing the test instruments (Vivien and O'Sullivan 2014). Tests are always made for a purpose, and the purpose has influenced the construct to be measured. There are a number of common purposes for testing listening including general language proficiency, achievement test, and diagnostic test. In order to benchmark and profile students' listening performance, a valid and reliable standardize listening comprehension test is required and need to be developed.

\subsection{Theoretical Underpinning}

This part will briefly highlight the tenets from the models, approach and the themes from the area of listening comprehension process, listening ability and constructing tests of listening to that form a conceptual framework. For listening comprehension process, the main model underpinning behind this study is by Geranpayeh and Taylor (2013) and supported by other researchers' point of view like Buck (2001) and Rost (2014). For constructing or designing a test, the main reference is on Weir's (2005) framework and Buck's (2001) suggestions on default listening construct for the general language proficiency test.

\subsubsection{Cognitive Processing Model}

This model highlights different processes involved in moving from the sound wave to an idea in the listeners' mind. This model developed by Geranpayeh and Taylor (2013) and used by the Cambridge English language assessment. This model is closely related to the model used for reading. In this model, the listening process is broken down into five levels with the lowest level is input decoding which involves in isolating phonemics units from the basic sound waves the listeners receive. The second level is a lexical search that involves identifying words from the individual phonemes. The next level is syntactic parsing which involves imposing a syntactic structure on a group of words to produce utterances, and this stage is equivalent to sentences in the written language. The fourth level is the meaning construction process which involves contextualizing the bare proposition in the third level and enriching it with the real-world knowledge and inferences to create a full proposition representing what speaker really meant. The final stage is discourse construction involves taking the new proposition and incorporating it into a representation of the whole discourse linking to everything that has gone before. The fourth and fifth level of the model complete the comprehension process.

\subsubsection{General Language Ability and Listening Ability Model}

This model formulated by Rost to map out the components of listening involves invalid assessment. It highlights how all five listening abilities overlap with general language ability. The listening abilities are phonological knowledge, lexical knowledge, syntactic knowledge, pragmatic knowledge, and general knowledge. Phonological knowledge is where a listener recognizes words in the stream of speech through knowledge of phonemes, allophonic variation, prosody, intonation, and stress. Lexical knowledge incorporates with knowing the meaning of words and their relationships with other words and collocations. Syntactic knowledge is about the parse speech at sentence and discourse levels. While general knowledge consists of knowledge about the world, this is including background knowledge, extralinguistic knowledge and other ways that people communicate.

\subsubsection{Socio-cognitive Framework for Developing Tests of Listening}

Adopting validity frameworks guarantees more valid and reliable tests with more systematic decision and it can be a pillar in validating the default listening construct to test learners' proficiency level. This framework could help a test developer to develop, validate and critique the test as it offers a systematic way of analyzing the features of listening task and how they contribute to context validity and the cognitive validity (Taylor and Geranpayeh 2011). Weir (2005) proposed four diagrammatic overviews of the macro-skills framework of reading, listening, speaking and writing. In his Socio-cognitive framework for validating listening, test identifies the evidence vital to develop a transparent and coherent validity argument as it is theoretically sound yet operationally useful when constructing and validating tests. The framework addressed five key elements to ensure fairness in constructing the listening test. The five key elements are context validity, theory-based 
validity, scoring validity, consequential validity, and criterion-related validity. The overall framework provides a map of what should be happening in terms of validation and just as important as when the test is completed. The Test takers and Cognitive validity elements of the model both represent the candidate in the test event. Weir (2005) believes that the characteristics of the test takers will directly impact how they process the task as defined by the parameters contained in the description of the test context. Context validity refers to the knowledge base that relates both task input and expected output and to the physical conditions or parameters that define the events. The parameters are related to both administrative settings such as security and the demand of the setting like duration of time for testing etc. Scoring validity refers to the fair and meaningful outcomes of test score or grades as a result of clearly establishing the links between all the decisions taken in developing the scoring system to the other elements of the model.

\subsubsection{The Integrated Approach}

There have been many historical developments in testing listening. Three of the developments which correspond to the theories of language learning and the different methods used to teach English for the past 60 years are the discrete-point approach, integrative approach and communicative approach (Buck 2001). These approaches are substantial as it is representing the growth of an expanding view of the listening construct. This view has emerged from the narrow view of listening as recognizing elements, through listening as language processing and then to the more current idea of listening as interpreting meaning in terms of communicative context. The integrative approach can be defined as a sentence-processing approach and Oller is one of the most believers in this approach. It attempted to move away from the discrete way of measuring language items separately by testing more than one items of language at a time. The integrated approach emphases on the process itself in which it has been regarded by the two level of processing language that is listening in the sense of the relationship between elements and as processing sequences of linguistic elements. In other words, it involves processing text in real time, to understand the literal and semantic meaning (Buck, 2001). However, it is often difficult to identify exactly what construct is being made either by a whole test or by individual items. The ideas about pragmatic expectancy grammar and the theories about language processing that underlie integrative test have not been seriously challenged. The drawback with integrative testing is that it tends to measure a range of language skills too narrow although the skills that they test are clearly important and fundamental. Listeners in integrative test grasp the basic linguistic information in the message. Due to language processing in the integrative test is seen as an isolated event, they do not relate the information that they grasp into the context.

\subsubsection{General Language Proficiency}

For the purpose of this research, a stand-alone general proficiency test of listening ability was developed by considering Buck's default listening construct which includes grammatical knowledge, discourse knowledge and pragmatic knowledge in it. According to Buck (2001), statement evaluation items, response evaluation items, longer information texts, and dictation are the four tasks type that is suitable to assess grammatical knowledge. To assess grammatical knowledge requires processing short samples of realistic language on a semantic level. Texts are suggested to be fast, with typical phonological modification and processed automatically. He further suggested that it is always a good idea to have a number of different task types to minimize the effect of one particular test methods. However, undergraduate students need a test with a broader listening construct, not just a test that assesses grammatical knowledge. A larger sample of discourse and device tasks that require the students to understand inferred meaning and pragmatic implications. Buck suggested starting with texts that contain information which can be put in grid or diagram. Other than that, narratives of interesting events are also appropriate which are normally easy to be summarized so that short-answer comprehension questions can be constructed. Students can be asked to fill in gaps on a summary of a story. Discourse and pragmatic knowledge are important too. Buck suggested writing tasks where the necessary information is scattered over the passage where the task will require testers to combine and summarize information. This task is suitable to access discourse patterns. Inferences about the main point, the gist, indirect statement, hints, pragmatic implications, indirect speech ask and interpreting the tone and attitude of speeches are suitable to assess pragmatic knowledge.

\subsubsection{Common European Framework of Reference (CEFR)}


Originally, CEFR is used to improve language teaching in countries of Europe. However recently, it is now being implemented worldwide and has been made use as a basis for reforming English language education in many countries including Malaysia. CEFR has been selected to benchmark the performance of current English language education system in Malaysia against the international standards and monitor developments in the years to 2025 ( English Language Standards and Quality Council 2015).

"The relevance of the CEFR to language education is that firstly it offers descriptive scheme as a starting point to review curriculum content, and secondly that the common reference levels provide a framework for putting curriculum objectives, entry testing, syllabus definition, materials organization, progress testing and certification of proficiency into one coherent local system that is appropriate to the context, related to the real world language ability, and easily communicated, internally and externally."

(English Language Education Reform in Malaysia: The Roadmap 2015-2025; pg:61)

The CEFR differs from other language frameworks in two ways. Firstly, CEFR highlights the competencies a learner needs (pragmatic, linguistics, sociolinguistics, strategic, intercultural) as a language user and it develops the familiar but inadequate four skills into a richer description of activities the learners undertake including spoken and written, reception, interaction, production and mediation. Secondly, it provides validated, scientifically calibrated descriptors of these different aspects of its descriptive scheme, except for intercultural competences and mediation (North, Ortega \& Sheehan, 2010). Learners have always been categorized as beginners, intermediate or advanced learner but CEFR avoids using relative labels as mentioned above because they mean very different things in different contexts. The labels used in CEFR refer learners based on the six reference levels. These levels are referred to basic users (A), the independent user (B) and proficiency user (C). Each of this level is divided into level 1 and 2, giving the full scale of 6 levels. The 'Can-Do' statements offer guidance to educators so that they can recognize and talk about ability levels. Test developers can use them as a guide in developing test and must decide which statements are most relevant to their context. It the available scales or statements do not match the context, it can be supplemented with 'Can-Do' statements from other sources, or new ones written for the context. Attempts to link or relate examinations to the CEFR should be seen as validation projects of the CEFR itself. Test developer must be able to justify the way they relate or translate the CEFR to their context partly by explaining features of their context.

\subsection{Prescribed Listening Performance Descriptors (PLPD)}

PLPD is referred to a detailed description of specific ESL listening abilities which incorporated listening specification of MUET, Rost's General Language Ability and Listening Ability, CEFR, EQUALS, DIALANG listening scale, and TOEIC Can-Do Level Table; in developing the descriptors. The rational for the development of PLPD is due to the fact that there is a need to have a standardized reference guide as a framework in which a reliable and valid instrument could be conceptualised. The description of the listening abilities is all based on "Can-Do" statements.

\subsection{Descriptive and comparative performance}

Data collected from the test will be analyzed in two ways: descriptive and comparative performance. After administering the test, the researcher will mark the test by referring to the marking scheme. For the purpose of descriptive performance, participants' score which will be based on the cut-score developed prior in the pilot study, will be analyzed. From the score too, participants' listening performance will be benchmarked by referring to Prescribed Listening Performance Descriptors. For the purpose of comparative performance, the participants' score will be compared with their MUET listening score, and program of study. The comparison between their SLCT score and MUET listening score is made to determine the criterion-related validity as part of the requirements in the socio-cognitive framework for developing a test of listening. 


\subsection{Profiling Listener Performance Standard}

Listener profile is a description of the characteristics of a group of students based on their listening performance standard. It is based on the level of expected performance after the respondents perform in the listening comprehension test (SLCT). The listeners will be profiled based on five performance standards. They are:

a) Primary Standard Performers,

b) Secondary Standard Performers,

c) Exceed Standard Performers,

d) Comprehensive Standard Performers or

e) Mastery Standard Performers

Being undergraduate students, the target listening performance standard is Exceed Standard Performers. Any students who are profiled as primary or secondary standard performers are categorized as below expectation performers. These performers will need to be paid more attention to as their listening performance could have to affect their academic as all lectures, any academic discussions, and activities in the university are conducted in the English language.

\section{Conceptual Framework}

By adopting from the models of Cognitive Processing by Geranpayeh and Taylor (2013), frameworks of Weir's Socio-cognitive framework for testing listening (2005), Common European Framework of Reference (CEFR); and themes discussed in literature review, the conceptual framework illustrates the relationship among the notions of developing Standardized Listening Comprehension Test (SLCT), benchmarking learners' listening performance and profiling listeners. This part begins with a discussion on the smaller elements in each notion and then proceeds to establish the connections that exit among the notions. Both the notions and connections are visualized in figure 1 below. With the aim of the study to develop a Listening Comprehension Test for NonNative Speaker (LisTeNS), and looking through the lenses of CEFR, Socio-cognitive Framework, and the Cognitive Processing Theory, benchmarking and profiling the learners occurs after obtaining the test score from the SLCT test. Thus, the big picture here is the development of listening comprehension test. The first process of developing test in this study encompasses all the stages in the Socio-cognitive framework for validating testing of listening (Weir 2005) which includes all the series of test instruments and checklist to support the test cognitively and theoretically; and the calculation for validity and reliability of the test so that the test developed is reliable and valid to be tested. The item validity, item reliability, item facility, and item discrimination were calculated after the pilot test so that any modification needed to improve the test could be done by the researcher. This process also includes the critical review by expert panels who review all aspects of the test as stated in the test instruments and checklists in making sure that it meets the level of quality as required for linking the test to the set of standards. Other than that, the experts have to review whether the relevant skills as stated in the Prescribed Listening Performance Descriptors (PLPD) linked with levels as described in the test specification, and clarify the acceptability of the cut scores that were calculated based on the pilot study. 


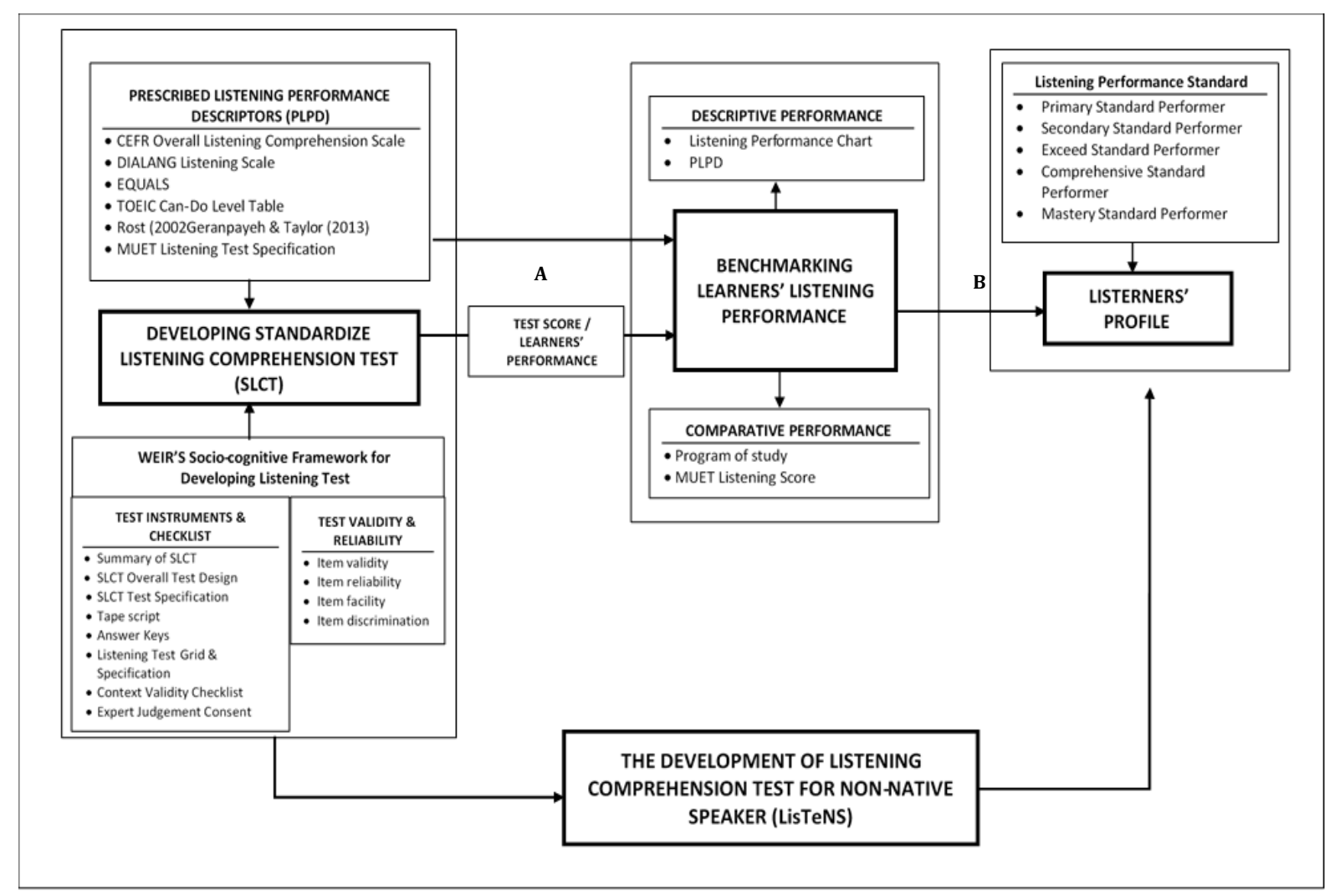

Figure 1 Conceptual Framework

The second notion of the framework involves in benchmarking the learners' listening performance. The learners' performance will be descriptively and comparatively benchmarked by using the test score. For descriptive performance, listening performance chart is used to determine whether learners have met the expectation of the listening performance standard. This chart consists of three types of expectation: below expectation, meet expectation and exceed expectation. Then, by referring to the cut scores, learners listening abilities' descriptions on what they can or cannot do will be identified by referring to PLPD. If the cut score in range with band 1, then the learners are categorized into Primary Standard; band 2 as Secondary Standard; band 3 as Exceed Standard; band 4 as Comprehensive Standard; and band 5 as Mastery standard. While for comparative performance, learners' test score is compared among the five programs of study and their MUET listening test score. These comparisons are important as it was stated in the Socio-cognitive framework as a consequential validity and criterion-related validity. The score interpretation is used for washback purposes. While the comparison of the test score with MUET listening score and program of study is done in order to determine the score value. The final notion of the framework focuses on profiling the learners' listening standard by categorizing the learners as either Primary Standard Performer, Secondary Standard Performer, Exceed Standard Performer, Comprehensive Standard Performer or Mastery Standard Performer. Their profiles are identified based on their test score and descriptive performance.

The notions in the conceptual framework are worthless without the clarification of how they are connected. Referring to figure 1, firstly it is clear that the process of developing LisTeNS to profile the listeners' performance requires a detailed process from planning until administering the test with several qualities to be met so that scores obtained from the test are reliable and valid to be used to benchmark the learners, and then to profile them based on the five standard performances. This also portrays the influence of an evidence-based approach of the Socio-cognitive framework and PLPD in constructing the test as there are many criteria and psychometrics issues to be covered including as listed in the list of test instruments and checklist, as well as the calculation of item validity, item reliability, item facility, and item discrimination. The arrows A and B show the connection between the test score and the listening descriptors with the benchmarking process and profiling the students. Lastly, the study is also interested in exploring the comparison between the learners' performance in SLCT with their program of study and their MUET listening score. 


\section{Conclusion}

The conceptual framework presented in this article is an initial but crucial part for bigger research especially on testing listening. This chapter has emphasized the tenets from models, an evidence-based approach, and instruments gained from the literature review and discussed the sub-notions (descriptive performance, comparative performance and listening performance standard) with their importance for the purpose of consequential validity and criterion-related validity. The deliberation of models, theoretical framework and themes have highlighted the three major notions (developing of SLCT, benchmarking listeners' performance and profiling listeners' standard) that becomes the pillars of the conceptual framework in developing Listening Comprehension Test for Non-Native Speaker (LisTeNS) to profile the learners' performance.

\section{References}

Selamat, Suzanah, and Kaur Gurnam Sidhu. 2011. "Student Perceptions of Metacognitive Strategy Use in Lecture Listening Comprehension." Language Education in Asia 185-198. Accessed November 23, 2015. http://dx.doi.org/10.5746/LEiA/11/V2/12/A02/Selamat_Sidhu.

Suchitra, Nair, Yew Li Koo, and Abu Bakar Kesumawati. 2014. "Exploring the Listening Processes of Preuniversity ESL Students." Procedia Social and Behavioral Sciences 118: 475-472. www.sciencedirect.com.

Robinson, Martin, Evelina D Galaczi, Coreen Docherty, Anthony King, and Hanan Khalifa. 2014. "Supporting national education reform: The Cambridge Malaysia Baseline Project." Cambridge English: Research Notes, November: 40-44. Accessed November 8, 2016. www.cambridgeenglish.org/research-notes.

2010-2015. "Official Portal Malaysian Examination Council." STPM and MUET Examination Reports. Accessed May 1, 2016. portal.mpm.edu.my.

Mehrabian, A. 1981. Silent Messages: Implicit Communication of Emotions and Attitudes. Wadsworth: Belmont.

McDevitt, T.M., E.P. Sheenan, and N McMenamin. 1991. "Self-reports of academic listening activities by traditional and non-traditional college students." College Student Journal 25: 478-489.

Brown, J.D. 2005. Testing in language programs: A comprehensive guide to English language assessment. New York: Mc Graw-Hill.

Vivien, Berry, and Barry O'Sullivan. 2014. "Assessing General Language Proficiency." Introducing Language Assessment. London: British Council Digital Services. Accessed November 15, 2016. https://www.britishcouncil.org/exam/aptis/research/project/assessment-literacy/general-languageproficiency.

Taylor, Lynda, and Ardeshir Geranpayeh. 2011. "Assessing listening for academic purposes: Defining and operationalising the test construct." Journal of English for Academic Purposes (Elsevier Ltd) (10): 89-101. doi:10.1016/j.jeap.2011.03.002.

Buck, Gary. 2001. Assessing Listening. Cambridge Language Assessment Series. Edited by J.Charles Anderson and Lyle F Bachman. Cambridge: Cambridge University Press.

English Language Standards and Quality Council. 2015. English Language Education Reform in Malaysia: The Roadmap 2015-2025. Ministry of Education Malaysia.

Weir. 2005. Language Testing and Validation An Evidence-Based Approach. Hampshire: Palgrave Macmillan.

North, Brian; Ortega, Angeles; Sheehan, Susan; 2010. A Core Inventory for General English. British Councils / EQUALS. Accessed February https://englishagenda.britishcouncil.org, 2017.

Mehrens, William A, and Irvin J Lehmann. 1991. Measurement and Evaluation in Education and Psychology. 4th. Belmont, CA: Wadsworth Thomson Learning.

Field, John. 2008. Listening in the Language Classroom. Cambridge: Cambridge University Press.

Vandergriff, Larry. 2007. "Listening: theory and practice in modern foreign language competence." Subject Centre for Languages, Linguistics and Area Studies Guide to Good Practice. February 22. Accessed January 3, 2016. http://www.llas.ac.uk/resources/gpg/67\#toc_1.

Mendelsohn, David. 2001. "Listening Comprehension: We've come a long way but..." Research Symposium, Fall: 33-37. Accessed February 16, 2016.

http://www.teslontario.net/publications/researchsympossium/ResearchSympossium2001.pdf.

Rost, Michael. 2002. Teaching \& Researching Listening. London: Longman.

D.Wolvin, Andrew, ed. n.d. Listening and Human Communication in the 21st Century. 2010: Wiley-Blackwell. 